\title{
Repression of the Notch pathway prevents liver damage in streptozotocin-induced diabetic mice
}

\author{
Eda Acikgoz ${ }^{1,2}$, Huseyin Aktug', Gurkan Yigitturk², Kenan Demir², Ummu Guven ${ }^{3}$, \\ Fahriye Duzagac $^{3}$, Fatih Oltulu ${ }^{2}$, Altug Yavasoglu ${ }^{2}$, Gulperi Oktem ${ }^{2,3}$
}

\author{
${ }^{1}$ Department of Histology and Embryology, Faculty of Medicine, Yuzuncu Yil University, \\ Van, Turkey \\ ${ }^{2}$ Department of Histology and Embryology, Faculty of Medicine, Ege University, Izmir, Turkey \\ ${ }^{3}$ Department of Stem Cell, Institute of Health Science, Ege University, Izmir, Turkey
}

\begin{abstract}
Introduction. Sunitinib is an oral inhibitor of vascular endothelial growth factor that is used to treat a variety of cancer. There are limited data regarding the effect of sunitinib on diabetes. In the liver, Notch signaling plays an important role in liver tissue development and homeostasis and its dysfunction is associated with liver pathologies. The aim of the present study is to investigate the effects of sunitinib on streptozotocin (STZ)-induced diabetic liver in mice models.

Material and methods. An experimental diabetes mellitus (DM) model was created in 28 male CD-1 mice. Twenty-eight male CD-1 mice divided in four groups $(\mathrm{n}=7$ each) were used; control mice $(\mathrm{C})$, control mice treated with sunitinib $(C+S)$, diabetic mice $(D M)$, and diabetic mice treated with sunitinib $(D M+S)$ for four weeks. The histopathological changes in the liver were examined by histochemistry and immunohistochemistry. Immunoreactivity of Notch1, Jagged1, DLL-1 and VEGF were evaluated in control and diabetic mice after sunitinib treatment.

Results. The significant morphological changes in the liver were mostly seen in hepatocytes that were hypertrophied in the DM mice, with an increased amount of eosinophilic granules; moreover, some hepatocytes contained empty vacuole-like structures. The livers of the DM mice revealed increased deposition of collagen fibers. After sunitinib treatment the hepatocytes and hepatic lobules had almost similar morphology to control mice. The immunoreactivities of Notch1, Jagged1, DLL-1 and VEGF in hepatocytes were significantly lower in the DM group when compared with the $\mathrm{C}, \mathrm{DM}+\mathrm{S}$ and $\mathrm{C}+\mathrm{S}$ group treated with sunitinib.

Conclusions. These results suggest that sunitinib effectively protects the liver from diabetes-induced damage through the inhibition of the Notch pathway. (Folia Histochemica et Cytobiologica 2017, Vol. 55, No. 3, 140-148)
\end{abstract}

Key words: diabetes; streptozotocin; mouse; liver; sunitinib; Notch1; Jagged1; DLL-1; VEGF; IHC

\section{Introduction}

Diabetes mellitus (DM) is one of the most prevalent endocrine metabolic disorders resulting from a defect in insulin secretion which results in hyperglycemia

\footnotetext{
Correspondence address: E. Acikgoz, Ph.D. Department of Histology and Embryology Faculty of Medicine Yuzuncu Yil University Faculty of Medicine Ege University Izmir, Turkey e-mail: acikgozedaa@gmail.com
}

and abnormalities in the metabolism of proteins, fats and carbohydrates. Worldwide, the incidence of DM has increased strikingly in recent decades. The two main types of diabetes are type 1 diabetes (T1D) and type 2 diabetes (T2D). T1D, also termed juvenile-onset or insulin-dependent diabetes, is a global health problem and its incidence is rapidly increasing [1]. T1D is a chronic autoimmune disease and a metabolic disorder which is characterized by selective destruction of insulin-producing $\beta$-cells in the islets of Langerhans, resulting in insulin deficiency and hyperglycemia [2]. DM-related long-term complications that involve blood vessels, kidney, eyes, 
and peripheral nervous system are the leading causes of morbidity and mortality in patients with DM, but only limited data are available on the possible association between diabetic complications and liver structure and function [3]. T1D patients frequently experience ketosis (hyperketonemia) because in a state of insulin deficiency, energy is derived mainly from fat stores [4]. Experimental T1D can be induced in animals by the administration of chemicals such as streptozotocin (STZ) and alloxan. STZ is widely used to induce insulin-dependent DM because of its toxic effects on pancreatic islets' $\beta$-cells [5].

The liver plays a central and crucial role in glucose homeostasis by maintaining a balance between uptake and storage of glucose as glycogen. This central role of the liver in the regulation of carbohydrate homeostasis is important to understand many biochemical alterations that occur in the diabetic liver. Although the prevalence of liver diseases among diabetics has been estimated to be between $17 \%$ and $100 \%$ [6], their pathomechanisms have not been well elucidated. In DM the failure of hepatocytes to respond to insulin contributes to uncontrolled gluconeogenesis, glycogenolysis and lipogenesis, which lead to such complications as steatohepatitis and hepatocellular carcinoma [7]. Cancer is more frequent among diabetic patients compared to non-diabetics. The studies on the association between DM and hepatocellular carcinoma (HCC) have shown that relative risks of HCC among people with diabetes are especially high soon after the diagnosis of diabetes had been established [8,9].

In recent years, structural and functional studies revealed that tyrosine kinases (TKs) act as the essential components in many signal transduction pathways and therefore become potential therapeutic targets. The tyrosine-kinase inhibitors (TKIs), small molecular and hydrophobic compounds, inhibit activity of TKs. TKIs have proven to be successful in the treatment of a wide variety of malignant diseases. Some inhibitors of tyrosine kinase, such as imatinib, erlotinib and sunitinib, have antihyperglycemic effects. It has been recently found that small-molecule protein tyrosine kinase inhibitors (PTKIs) can prevent or even reverse the development of diabetes in an established animal model [10,11]. Little et al. [12] suggest that TKIs have anti-diabetic effects in both T1D and T2D, and that this could be mediated by both improved $\beta$-cell survival and decreased insulin resistance in the main target tissues [13]. Sunitinib, chemically known as SU-11248, is an oral oxindole multi-targeted receptor tyrosine kinase (RTK) inhibitor that exhibits potent antiangiogenic and antitumor activities. Sunitinib has been identified as a potent inhibitor of vascular endothelial growth factor receptors (VEGFR type 1 and 2), platelet-derived growth factor receptors (PDGFR- $\alpha$ and PDGFR- $\beta$ ), stem cell factor receptor (KIT) in both biochemical and cellular assays $[14,15]$. Sunitinib has been recently shown to have potential therapeutic utility for the treatment of patients with DM $[16,17]$.

Notch signaling pathway is a highly conserved cell signaling system present in most multicellular organisms. The Notch pathway regulates cell proliferation, differentiation, cell fate specification and organ development during embryonic and adult life. In the liver, Notch signaling has recently been recognized as a key player in glycogenolysis and gluconeogenesis processes, with abnormal activation of Notch signaling in hepatocytes leading to hyperglycemia and fatty liver disease [18]. Notch itself is a transmembrane receptor that transduces short-range signals by interacting with cell surface ligands such as jagged and delta that are associated with the surface of neighboring cells. Upon activation by ligand binding, Notch is proteolytically cleaved within its transmembrane domain by presenilin-1/c secretase resulting in the release of a Notch intracellular domain (NICD) which translocates to the nucleus where it activates the transcription of downstream target genes.

Vascular endothelial growth factor (VEGF) plays a key role in vasculogenesis and angiogenesis by stimulating endothelial cell mitosis and migration in many tissues. VEGF appears to play a central role in the microvascular complications in T1D and T2D [19]. Interaction between VEGF and Notch signaling has been reported in diabetes [20].

Several studies showed that sunitinib was used for the treatment of a wide range of diseases, including infectious diseases, alongside autoimmune and malignant disorders. The use of sunitinib is becoming more common. Therefore, it seems to be important to know whether sunitinib has a therapeutic potential in diabetes. The aim of the present study was to investigate the effects of sunitinib in a mouse model of streptozotocin-induced diabetes by the use of histochemistry and immunohistochemistry.

\section{Material and methods}

Animals. In this study, 28 male CD-1 mice aged 8 weeks and weighing 20-30 g were selected. Animals were fed $a d$ libitum and housed under standard laboratory conditions (12:12 h light:dark cycle, $24^{\circ} \mathrm{C}$ room temperature, $\sim 60 \%$ humidity). The experimental procedures were approved by the Committee for Animal Research of the Ege University, Turkey. All animal studies strictly conformed to the animal experiment guidelines of the Committee for Human Care. 
Diabetes was induced in 14 mice by intraperitoneal (ip) injection of single dose of $60 \mathrm{mg} / \mathrm{kg}$ STZ [2-deoxy-2-(3-(methyl-3-nitrosoureido)-D-glucopyranose] (Sigma-Aldrich, St Louis, MO, USA) (STZ was dissolved in $0.9 \% \mathrm{NaCl}$, adjusted to $\mathrm{pH} 4.0$ with $0.2 \mathrm{M}$ sodium citrate buffer). In the control group the level of blood glucose was below 120 $\mathrm{mg} / \mathrm{dL}(\mathrm{n}=7)$. DM was verified after $48 \mathrm{~h}$ by evaluating blood glucose levels with the use of glucose oxidase reagent strips (Boehringer, Mannheim, Germany) from tail vein. The blood glucose levels were $250 \mathrm{mg} / \mathrm{dL}$ and higher in the diabetic mice. The 14 diabetic mice were randomly divided into 2 groups: DM group received $0.2 \mathrm{~mL}$ of $0.9 \%$ saline $(\mathrm{n}=7)$, whereas diabetic mice treated with sunitin$\mathrm{ib}$, designed as $\mathrm{DM}+\mathrm{S}$ group $(\mathrm{n}=7)$, received $1.5 \mathrm{mg} / \mathrm{kg} /$ day sunitinib in $0.2 \mathrm{~mL}$ of $0.9 \%$ saline. Saline or sunitinib were administered to diabetic mice by ip injections for 4 weeks. Then, the animals were euthanized and the liver was removed for histopathological evaluation.

Histopathological examination. For histological studies, all animals were anesthetized with ip injection of ketamine $(40 \mathrm{mg} / \mathrm{kg})$ and xylazine $(4 \mathrm{mg} / \mathrm{kg})$ and perfused with $200 \mathrm{~mL}$ of $4 \%$ formaldehyde in $0.1 \mathrm{M}$ phosphate-buffered saline (PBS). Formalin-fixed liver samples were processed into paraffin blocks, sectioned at $5 \mu \mathrm{m}$ and stained with hematoxylin and eosin (H\&E) and Masson's trichrome method. All sections were photographed using an Olympus C-5050 digital camera (Olympus Optical Co., Tokyo, Japan) mounted on an Olympus BX51 microscope.

Immunohistochemistry. $5 \mu$ m-thick sections were cut using semi-motorized rotary microtome (Leica MR 2145); they were then dewaxed and rehydrated through a graded ethanol series using routine protocols. Sections were then washed with distilled water and PBS for $10 \mathrm{~min}$, then treated with $2 \%$ trypsin (Sigma-Aldrich) in $50 \mathrm{mM}$ Tris buffer (pH 7.5), at $37^{\circ} \mathrm{C}$ for $15 \mathrm{~min}$. Sections were delineated with a Dako pen (Dako, Glostrup, Denmark) and incubated in a solution of $3 \% \mathrm{H}_{2} \mathrm{O}_{2}$ for $15 \mathrm{~min}$ to inhibit endogenous peroxidase activity. Next, the sections were incubated with primary antibodies directed against DLL1 (1:100; bs-7435R Bioss, Beijing, China), Notch1 (1:1000; bs-1196R Bioss), Jagged1 (1:100; bs-1448R, Bioss), VEGF (1:100; sc-7269, Santa Cruz Biotechnology, Inc., Santa Cruz, CA, USA) all for $24 \mathrm{~h}$ at $4^{\circ} \mathrm{C}$ in a humid chamber. Sections were then incubated with biotinylated secondary antibody and then with streptavidin conjugated to horseradish peroxidase (both from Zymed Histostain-Plus Peroxidase kit, 85-9043, Zymed Laboratories, San Francisco, CA, USA) prepared according to manufacturer's instruction for $30 \mathrm{~min}$ each. Finally, sections were incubated with 3',3'-diaminobenzidine (DAB) (Dead End Colorimetric TUNEL system, Promega, Madison, WI, USA) prepared according to manufacturer's instruction, for $5 \mathrm{~min}$ to reveal immune labeling. All dilu- tions and thorough washes between stages were performed with PBS. Sections were counterstained with Mayer's hematoxylin (Zymed Laboratories). After washing with tap water, sections were dehydrated through a graded ethanol series, cleared in xylene and mounted with Entellan (Merck, Darmstadt, Germany). Microphotographs were obtained using Olympus C-5050 digital camera mounted on an Olympus BX51 microscope. The number of positive cells was assessed systematically by scoring at least 100 cells per 10 view-fields of tissue sections at $\times 20$ magnification independently by three histologists.

Semiquantitative assessment of the immunoreactivity of the studied proteins. VEGF, DLL-1, Jagged 1 and Notch-1 immunohistochemical semi-quantitation was determined using the modified H-score (Histoscore). H-score was calculated by a semi-quantitative assessment of both the intensity of staining (graded as: 0, non-staining; 1, weak; 2, median; 3, strong) and the percentage of positive cells. The range of possible scores was from 0 to 300. Expression level of each component was categorized as low or high according to the median value of the $\mathrm{H}$-score.

Statistical analysis. Data analyses were performed by Statistical Package for Social Sciences software, version 15.0 for Windows (SPSS, Chicago, IL, USA). The groups of parametric variables were compared by Student's t-test and analysis of variance. The groups of nonparametric variables were compared by Mann-Whitney U test. Results were given as mean + SEM. The value of $p<0.05$ was accepted as statistically significant and $\mathrm{p}<0.001$ was accepted as statistically highly significant.

\section{Results}

\section{Blood glucose concentration}

Higher blood glucose levels were found in all the diabetic mice compared to the control group. The increase in blood glucose was observed $48 \mathrm{~h}$ after the STZ injection and was maintained throughout the study period (Table 1).

\section{Histopathological analysis of the liver of diabetic mice treated with sunitinib}

Examination of $\mathrm{H} \& \mathrm{E}$-stained sections of liver of control mice showed normal histological architecture and normal lobular pattern with a centrilobular vein and radiating irregular anastomosing plates of hepatocytes with intervening sinusoids lined with sinusoidal endothelial cells (Suppl. Fig. 1C). The characteristic histological alteration in the liver of STZ-treated mice was hypertrophy of hepatocytes. Many hypertrophic hepatocytes showed dense cytoplasm with an increased amount of eosinophilic granules. In some 
Table 1. Blood glucose concentration of control, STZ- and sunitinib-treated mice

\begin{tabular}{|l|c|c|c|c|}
\hline Time/group & Control mice & Control + sunitinib & Diabetic mice & Diabetic + sunitinib \\
\hline Beginning of the study & $93.34 \pm 5.1$ & $92.80 \pm 4.2$ & $565.51 \pm 25.2^{*}$ & $567.14 \pm 23.9^{*}$ \\
\hline End of the study & $95.10 \pm 3.2$ & $90.12 \pm 4.4$ & $546.10 \pm 57.7^{*}$ & $538.41 \pm 40.4^{*}$ \\
\hline p value for time parameter & NS & NS & NS & NS \\
\hline
\end{tabular}

Values are expressed in $\mathrm{mg} / \mathrm{dL}$ as mean $\pm \mathrm{SEM} .{ }^{*}$ Statistically significant differences as compared to the control group $(\mathrm{p}<0.05)$. NS - not significant $(\mathrm{p}>0.05)$
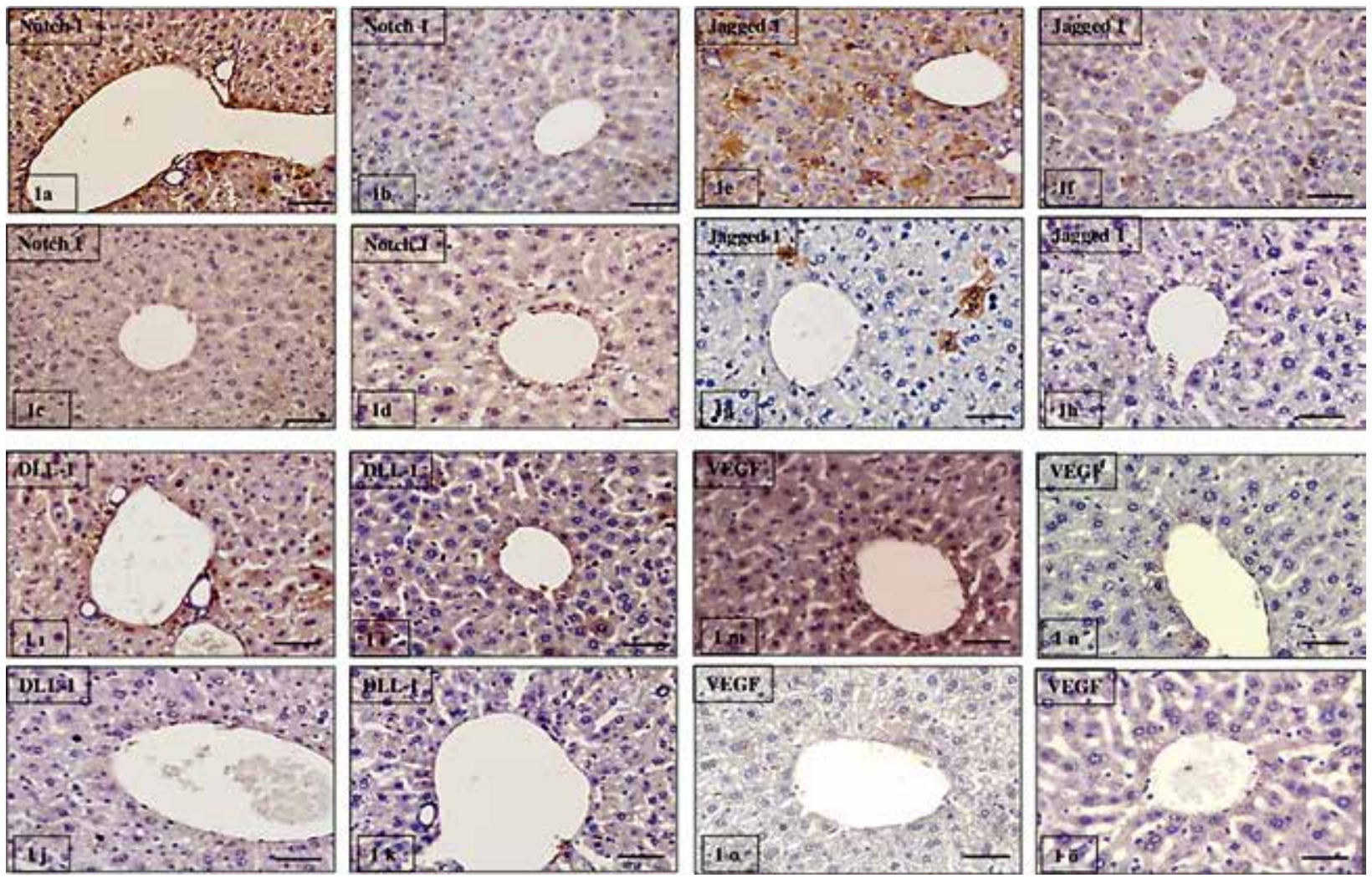

Figure 1. Notch 1, Jagged 1, DLL-1 and VEGF immunoreactivity in the liver of diabetic and control mice treated with sunitinib. Diabetic mice (DM): 1a, 1e, 1, 1m; diabetic mice treated with sunitinib (DM + S): 1b, 1f, 1i, 1n; control mice (C group): 1c, 1g, 1j, 1o; control mice treated with sunitinib $(\mathrm{C}+\mathrm{S})$ : 1d,1h, 1k, 1ö.The immunohistochemical staining was performed as described in Material and methods. Scale bar: $50 \mathrm{~mm}$.

cases, the cytoplasm of hepatocytes contained empty vacuole-like spaces (Suppl. Fig. 1A). H\&E-stained liver sections of the sunitinib treated mice showed that morphology of most of hepatic lobules was almost similar to that of the normal control group (Suppl. Fig. 1C). Also, H\&E-stained sections of the liver of the normal non-diabetic mice treated for four weeks with sunitinib $(C+S)$ were similar to the normal control group (Suppl. Fig. 1D).

The Masson Trichrome histochemical staining of the liver was applied to assess the presence of fibrosis. The livers of control mice appeared normal without signs of fibrosis (Suppl. Fig. 2C). The livers of the DM group revealed increased deposition of collagen fibers (Suppl. Fig. 2A). The livers of diabetic mice treated with sunitinib (Suppl. Fig. 2B) and nondiabetic mice treated with sunitinib (Suppl. Fig. 2D) showed moderate deposition of collagen fibers.

\section{Immunohistochemical analysis}

\section{Notch1 immunoreactivity}

In liver sections of the diabetic mice, strong immunopositive reactions (Fig. 1a) were detected for Notch1 when compared with the control (Fig. 1c and Fig. 2) $(p<0.001)$. Notch1 immunoreactivity in the hepatocytes was significantly lower in the sunitinib-treated mice compared with the diabetes group $(\mathrm{p}<0.05)$ 


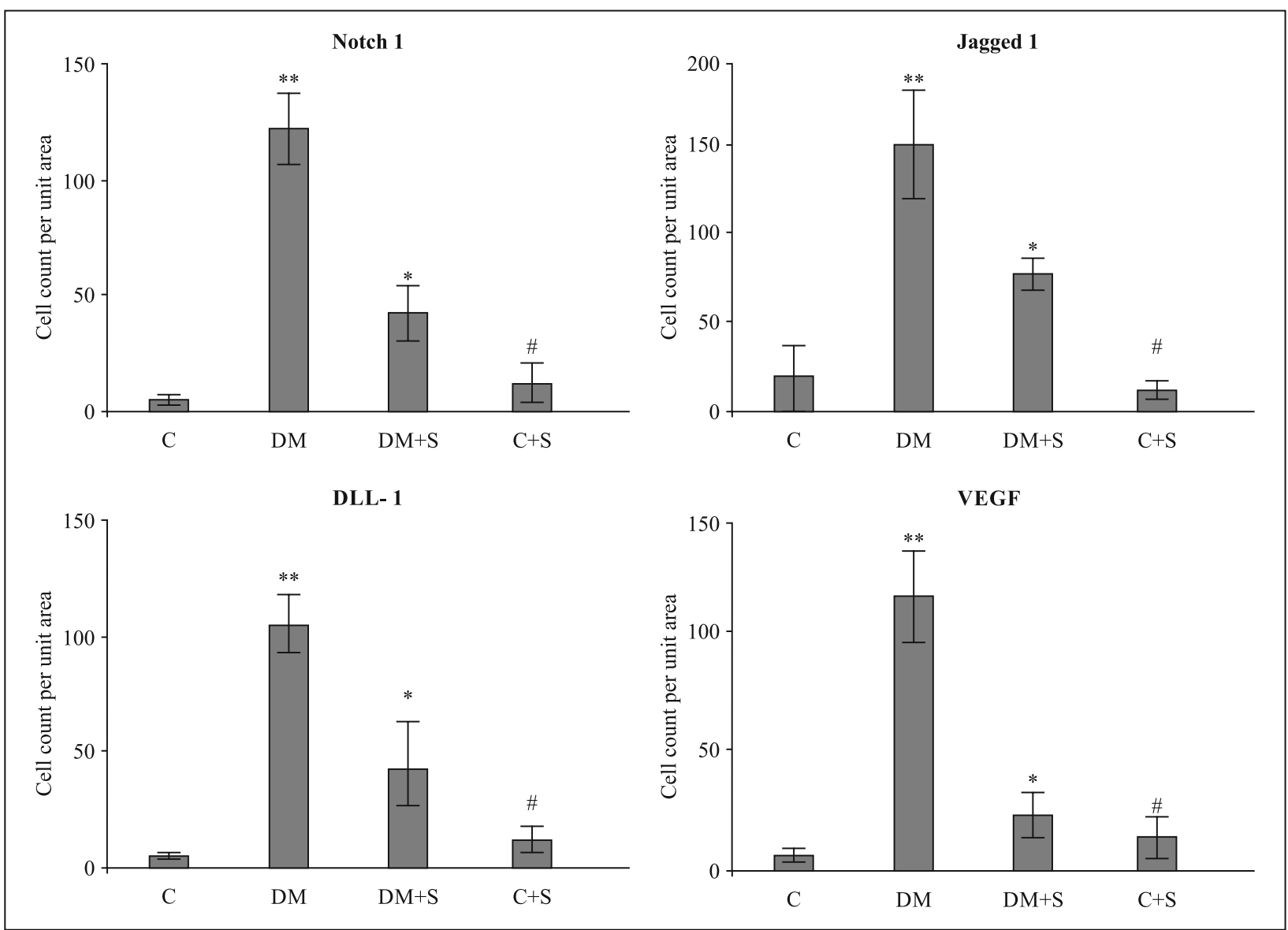

Figure 2. Semiquantitative analysis of Notch1, Jagged1, DLL-1 and VEGF immunoreactivity in the livers of control (C), diabetic $(D M)$, as sunitinib-treated control $(C+S)$ and sunitinib-treated diabetic mice $(D M+S)$. Statistical analyses showed strong statistically significant differences between diabetic mice and sunitinib-treated diabetic mice $(\mathrm{p}<0.001)$. The differences between normal control $(C)$ and sunitinib-treated normal mice $(C+S)$ were statistically not significant $(\mathrm{p}>0.05)$. The number of the immunoreactive cells per unit area was used to determine to intensity of the immunoreactivity. ${ }^{*} \mathrm{p}<0.05,{ }^{*} \mathrm{p}<0.001,{ }^{\#} \mathrm{p}>0.05$ vs. control mice.

(Fig. 1b and Fig. 2). There was no difference between the $\mathrm{DM}+\mathrm{S}$ group and the $\mathrm{C}+\mathrm{S}$ group (Fig. 1d and Fig. 2).

\section{Jagged1 immunoreactivity}

Jagged1 immunostaining was weak in the livers of control mice (Fig. 1g). In the DM group, Jagged1 immunoreactivity was strong in the liver (Fig. 1e) when compared to the control group $(\mathrm{p}<0.001)$ (Fig. 2). In the livers of sunitinib-treated diabetic mice the immunoreactivity of Jagged1 (Fig. 1f) was significantly lower than in the DM group. In $\mathrm{C}+\mathrm{S}$ group (Fig. 1h), Jagged1 immunoreactivity was similar to that in the control group ( $\mathrm{p}>0.05$ ) (Fig. 2).

\section{DLL-1 immunoreactivity}

The immunoreactivity of DLL-1 was weak in livers of control mice (Fig. 1j) and control mice treated with sunitinib (Fig. 1k). In diabetic mice, DLL-1 immunoreactivity was stronger in the liver (Fig. 11) than in the control group (p < 0.05) (Fig. 2). After sunitinib treatment of the diabetic mice the immunoreactivity of DLL-1 (Fig. 1i) significantly decreased.

\section{VEGF immunoreactivity}

We observed significant differences in the hepatic VEGF expression between diabetic mice and diabetic mice treated with sunitinib (DM $+\mathrm{S}$ group) $(p<0.001)$ (Fig. 2). The hepatocytes of pericentral zone showed positive immunoreactivity for VEGF. The number of VEGF-positive cells in in the liver of diabetic mice (Fig. 1m) was higher than in diabetic mice treated with sunitinib (Fig. 1n). In livers of control mice treated with sunitinib (Fig. 10̈), VEGF immunoreactivity appeared similar to that of control mice (Fig. 1o and Fig. 2) ( $p>0.05)$. 


\section{Discussion}

The effect of diabetes mellitus in various tissues is well recognized, but only limited data is known about the relationship between diabetic complications and liver function. There are different types of drugs used in the treatment of diabetes. To investigate the signaling pathways associated with diabetes it is important to ensure the development of new drugs. Therefore, in the present study we investigated the effect of STZ-induced diabetes on mouse liver and tried to determine whether the tyrosine kinase inhibitor treatment prevented the diabetes-induced liver injury.

Streptozotocin is derived from Streptomyces achromogenes and is used as a diabetogenic agent for the induction of diabetes. STZ produces toxic radicals which destroy pancreatic $\beta$-cells and cause diabetes in experimental animals. However, the action mechanism of STZ is not directed at pancreatic $\beta$-cells only, as other organs such as the liver, kidney and bone marrow are also affected by the STZ administration. Several studies reported that streptozotocin caused morphological biochemical, and pathological changes in many organs including the liver [21-24]. In this study, histological investigations showed hypertrophic hepatocytes with an increased amount of eosinophilic granules in STZ-treated mice. In the same group, the hepatocytes' cytoplasm contained empty vacuole-like spaces. Similarly, Oršolić et al. found cellular vacuolization, cytoplasmic eosinophilia in the liver of diabetic mice [25]. The present study also showed the areas of fibrosis in the liver of mice belonging to the STZ group. Similar histopathological findings in the liver of diabetic rats were described by de Cavanagh et al. [26].

Sunitinib is a multitargeted receptor tyrosine kinase inhibitor that has potent antitumor and antiangiogenic activities, and has been shown recently to be a novel therapeutic molecule for the treatment of diabetic patients [27]. Recently, there has been several publications related to the effects of sunitinib in T1D and T2D [11, 13, 16]. Agostino et al. reported that sunitinib significantly decreased the concentration of blood glucose in diabetic patients [16]. We found that the sunitinib treated diabetic mice, hypertrophy of hepatocytes, eosinophilic granules and the presence of fibrosis decreased. In result of all the morphological findings obtained from histopathological analysis, it was concluded that sunitinib has a protective effect against the hepatotoxicity produced by STZ diabetes.

Signal transduction pathways are important to understand the physiological and pathophysiological mechanisms of biological and pathological processes. The knowledge of the pathways involved in the pathomechanisms of diabetes is necessary for the develop- ment of new drugs for the management of diabetes. The Notch signaling pathway plays very important roles in many biological processes such as cell fate decisions, cell proliferation, apoptosis, and cancer. Notch signaling pathway is involved in the regulation of liver metabolism since increased expression of Notch receptors and ligands was observed in liver injury [28]. Although Notch activation could contribute to liver regeneration and repair, sustained activation of Notch signaling is associated with liver diseases [28-30]. In the liver, Notch signaling has recently been recognized as a key player in glycogenolysis and gluconeogenesis processes [30]. Moreover, Notch may regulate hepatic vasculature, inflammation and liver fibrosis [29]. Valenti et al. reported that Notch regulates liver glucose and lipid homeostasis through forkhead box protein $\mathrm{O} 1$ (FoxO1), a transcription factor known to be the main target of insulin signaling [30]. We found that after sunitinib treatment of diabetic mice, the immunoexpression of Notch1, Jagged1 and DLL-1 decreased significantly. At the same time, it affects immunoexpression of VEGF. The possible effect of sunitinib on VEGF immunoexpression may be due to targeting of VEGF receptors [31] or Notch-VEGF interactions [32]. Recently, the activation and upregulation of Notch ligands and receptors in injured livers has been associated with liver fibrosis [29]. A previous study suggested that Jag-1 is highly expressed in injured livers and stimulates alpha-smooth muscle actin and collagen production [33]. Notch inhibition by $\gamma$-secretase inhibitor reduced liver fibrosis [34]. When we used sunitinib in the treatment of diabetic mice, collagen deposits decreased significantly. Sunitinib may prevent liver fibrosis via inhibition of the Notch signaling pathway. Tuques et al. demonstrated that sunitinib has antifibrotic activity in liver [35], probably via targeting the PDGF and VEGF pathways [36].

Several signaling pathways play major roles in metabolic diseases, especially in receptor-targeted therapies. In-depth understanding of the cross-talk between signaling pathways may provide alternative solutions for the treatment of these diseases. Notch and RTKs act together to regulate cell fate. There is also some evidence that RTKs induce the expression of the Notch in particular by targeting Hes-1 [37]. Therefore, inhibitors targeting RTKs and signaling associated with RTKs could be therapeutically useful for the treatment of metabolic disorders such as diabetes.

Sunitinib is a small molecule tyrosine kinase inhibitor that is able to inhibit members of the RTK families containing vascular endothelial growth factor receptors (VEGFR), stem cell factor receptor (KIT), platelet-derived growth factor receptors (PDGFR) 
$[14,15,38]$. Among the RTKs, VEGF receptors play a key role in vasculogenesis and angiogenesis $[39,40]$. VEGF also regulates monocyte/macrophage migration and infiltration of tissues [41, 42]. Recent studies have demonstrated that VEGF signaling pathway may be associated with diabetes [43, 44]. The study by Cha et al. demonstrated that high glucose concentration increased VEGF expression in diabetic kidney [45]. Tsai et al. also reported that high glucose increases VEGF expression in human synovial fibroblasts via the ROS, PI3K, Akt, c-Jun and AP-1 signaling pathway [46]. In the present study, we have shown that that VEGF immunoexpression was increased in the livers of STZ-induced diabetic mice, and that their treatment with sunitinib decreased VEGF immunoreactivity. VEGF expression in diabetic tissues may be associated with hypoxic conditions. Hypoxia induces the expression of VEGF by the transcription factor hypoxia-inducible factor- $1 \alpha$ (HIF- $1 \alpha)$. HIF- $1 \alpha$ promotes new blood vessel formation through VEGF in some conditions [47]. Number of studies demonstrated that elevated glucose concentrations increased HIF- $1 \alpha$ levels in diabetes [48, 49]. Haligur et al. showed that HIF- $1 \alpha$ levels in hepatocytes increased in early stages of DM [50]. Enhanced expression of VEGF plays an important role in the pathogenesis of DM [42]. Our studies also confirm previous reports $[48,50]$ demonstrating increased levels of VEGF lead to degenerative effects on liver. Therefore, blocking VEGF with sunitinib may represent an alternative treatment strategy for the treatment of T1D.

Our study showed that DM affects the structure of hepatocytes and liver tissue in STZ-induced diabetic mice. The results demonstrated that VEGF and Notch signaling pathway are associated with DM-related liver pathological changes. In addition, the study showed the beneficial effects of sunitinib in the prevention of diabetes-associated liver pathology occur via the reduced expression of Notch1, Jagged1, DLL-1 and VEGF. Further studies are necessary to check if sunitinib may be considered as an effective drug for the protection of liver in diabetes.

\section{References}

1. Patterson CC, Dahlquist GG, Gyürüs E, et al. EURODIAB Study Group. Incidence trends for childhood type 1 diabetes in Europe during 1989-2003 and predicted new cases 200520: a multicentre prospective registration study. Lancet. 2009; 373(9680): 2027-2033, doi: 10.1016/S0140-6736(09)60568-7, indexed in Pubmed: 19481249.

2. van Belle TL, Coppieters KT, von Herrath MG. Type 1 diabetes: etiology, immunology, and therapeutic strategies. Physiol Rev. 2011; 91(1): 79-118, doi: 10.1152/physrev.00003.2010, indexed in Pubmed: 21248163.

3. Perkins BA, Bril V. Emerging therapies for diabetic neuropathy: a clinical overview. Curr Diabetes Rev. 2005; 1(3):
271-280, doi: 10.2174/157339905774574338, indexed in Pubmed: 18220603 .

4. Jain SK, McVie R, Bocchini JA. Hyperketonemia (ketosis), oxidative stress and type 1 diabetes. Pathophysiology. 2006; 13(3): 163-170, doi: 10.1016/j.pathophys.2006.05.005, indexed in Pubmed: 16782314.

5. Ohno T, Horio F, Tanaka S, et al. Fatty liver and hyperlipidemia in IDDM (insulin-dependent diabetes mellitus) of streptozotocin-treated shrews. Life Sci. 2000; 66(2): 125-131, doi: 10.1016/s0024-3205(99)00570-6, indexed in Pubmed: 10666008.

6. Al-Hussaini AA, Sulaiman NM, Alzahrani MD, et al. Prevalence of hepatopathy in type 1 diabetic children. BMC Pediatr. 2012; 12: 160, doi: 10.1186/1471-2431-12-160, indexed in Pubmed: 23039762.

7. Takamatsu S, Noguchi N, Kudoh A, et al. Influence of risk factors for metabolic syndrome and non-alcoholic fatty liver disease on the progression and prognosis of hepatocellular carcinoma. Hepatogastroenterology. 2008; 55(82-83): 609-614, indexed in Pubmed: 18613418.

8. Inoue M, Iwasaki M, Otani T, et al. Diabetes mellitus and the risk of cancer: results from a large-scale population-based cohort study in Japan. Arch Intern Med. 2006; 166(17): 1871-1877, doi: 10.1001/archinte.166.17.1871, indexed in Pubmed: 17000944.

9. Wang C, Wang X, Gong G, et al. Increased risk of hepatocellular carcinoma in patients with diabetes mellitus: a systematic review and meta-analysis of cohort studies. Int J Cancer. 2012; 130(7): 1639-1648, doi: 10.1002/ijc.26165, indexed in Pubmed: 21544812.

10. Hägerkvist R, Sandler S, Mokhtari D, et al. Amelioration of diabetes by imatinib mesylate (Gleevec): role of beta-cell NF-kappaB activation and anti-apoptotic preconditioning. FASEB J. 2007; 21(2): 618-628, doi: 10.1096/fj.06-6910com, indexed in Pubmed: 17135364.

11. Louvet C, Szot GL, Lang J, et al. Tyrosine kinase inhibitors reverse type 1 diabetes in nonobese diabetic mice. Proc Natl Acad Sci USA. 2008; 105(48): 18895-18900, doi: 10.1073/ pnas.0810246105, indexed in Pubmed: 19015530.

12. Little PJ, Cohen N, Morahan G. Potential of small molecule protein tyrosine kinase inhibitors as immuno-modulators and inhibitors of the development of type 1 diabetes. ScientificWorldJournal. 2009; 9: 224-228, doi: 10.1100/tsw.2009.28, indexed in Pubmed: 19347233.

13. Mokhtari D, Welsh N. Potential utility of small tyrosine kinase inhibitors in the treatment of diabetes. Clin Sci (Lond). 2009; 118(4): 241-247, doi: 10.1042/CS20090348, indexed in Pubmed: 19886867.

14. Abrams TJ, Lee LB, Murray LJ, et al. SU11248 inhibits KIT and platelet-derived growth factor receptor beta in preclinical models of human small cell lung cancer. Mol Cancer Ther. 2003; 2(5): 471-478, indexed in Pubmed: 12748309.

15. Mendel DB, Laird AD, Xin X, et al. In vivo antitumor activity of SU11248, a novel tyrosine kinase inhibitor targeting vascular endothelial growth factor and platelet-derived growth factor receptors: determination of a pharmacokinetic/ pharmacodynamic relationship. Clin Cancer Res. 2003; 9(1): 327-337, indexed in Pubmed: 12538485.

16. Agostino NM, Chinchilli VM, Lynch CJ, et al. Effect of the tyrosine kinase inhibitors (sunitinib, sorafenib, dasatinib, and imatinib) on blood glucose levels in diabetic and nondiabetic patients in general clinical practice. J Oncol Pharm Pract. 2011; 17(3): 197-202, doi: 10.1177/1078155210378913, indexed in Pubmed: 20685771. 
17. Templeton A, Brändle M, Cerny T, et al. Remission of diabetes while on sunitinib treatment for renal cell carcinoma. Ann Oncol. 2008; 19(4): 824-825, doi: 10.1093/annonc/mdn047, indexed in Pubmed: 18326519.

18. Bi P, Kuang S. Notch signaling as a novel regulator of metabolism. Trends Endocrinol Metab. 2015; 26(5): 248-255, doi: 10.1016/j.tem.2015.02.006, indexed in Pubmed: 25805408.

19. Tremolada G, Lattanzio R, Mazzolari G, et al. The therapeutic potential of VEGF inhibition in diabetic microvascular complications. Am J Cardiovasc Drugs. 2007; 7(6): 393-398, doi: 10.2165/00129784-200707060-00002, indexed in Pubmed: 18076206.

20. Lin CL, Wang FS, Hsu YC, et al. Modulation of notch-1 signaling alleviates vascular endothelial growth factor-mediated diabetic nephropathy. Diabetes. 2010; 59(8): 1915-1925, doi: 10.2337/db09-0663, indexed in Pubmed: 20522599.

21. Sönmez MF, Karabulut D, Kilic E, et al. The effects of streptozotocin-induced diabetes on ghrelin expression in rat testis: biochemical and immunohistochemical study. Folia Histochem Cytobiol. 2015; 53(1): 26-34, doi: 10.5603/FHC. a2015.0006, indexed in Pubmed: 25765092.

22. Ayuob NN, Murad HAS, Ali SS. Impaired expression of sex hormone receptors in male reproductive organs of diabetic rat in response to oral antidiabetic drugs. Folia Histochem Cytobiol. 2015; 53(1): 35-48, doi: 10.5603/FHC.a2015.0005, indexed in Pubmed: 25765091.

23. Laguens RP, Candela S, Hernández RE, et al. Streptozotocin-induced liver damage in mice. Horm Metab Res. 1980; 12(5): 197-201, doi: 10.1055/s-2007-996241, indexed in Pubmed: 6446516 .

24. Afrin R, Arumugam S, Soetikno V, et al. Curcumin ameliorates streptozotocin-induced liver damage through modulation of endoplasmic reticulum stress-mediated apoptosis in diabetic rats. Free Radic Res. 2015; 49(3): 279-289, doi: 10.3109/10715762.2014.999674, indexed in Pubmed: 25536420.

25. Oršolić N, Sirovina D, Končić MZ, et al. Effect of Croatian propolis on diabetic nephropathy and liver toxicity in mice. BMC Complement Altern Med. 2012; 12: 117, doi: 10.1186/1472-6882-12-117, indexed in Pubmed: 22866906.

26. de Cavanagh EM, Inserra F, Toblli J, et al. Enalapril attenuates oxidative stress in diabetic rats. Hypertension. 2001; 38(5): 1130-1136, doi: 10.1161/hy1101.092845, indexed in Pubmed: 11711510.

27. Lutz SZ, Ullrich A, Häring HU, et al. Sunitinib specifically augments glucose-induced insulin secretion. Cell Signal. 2017; 36: 91-97, doi: 10.1016/j.cellsig.2017.04.018, indexed in Pubmed: 28449948.

28. Morell CM, Strazzabosco M. Notch signaling and new therapeutic options in liver disease. J Hepatol. 2014; 60(4): 885-890, doi: 10.1016/j.jhep.2013.11.028, indexed in Pubmed: 24308992.

29. Geisler F, Strazzabosco M. Emerging roles of Notch signaling in liver disease. Hepatology. 2015; 61(1): 382-392, doi: 10.1002/hep.27268, indexed in Pubmed: 24930574.

30. Valenti L, Mendoza RM, Rametta R, et al. Hepatic notch signaling correlates with insulin resistance and nonalcoholic fatty liver disease. Diabetes. 2013; 62(12): 4052-4062, doi: 10.2337/db13-0769, indexed in Pubmed: 23990360.

31. Faivre S, Delbaldo C, Vera K, et al. Safety, pharmacokinetic, and antitumor activity of SU11248, a novel oral multitarget tyrosine kinase inhibitor, in patients with cancer. J Clin Oncol. 2006; 24(1): 25-35, doi: 10.1200/JCO.2005.02.2194, indexed in Pubmed: 16314617.
32. Thomas JL, Baker K, Han J, et al. Interactions between VEGFR and Notch signaling pathways in endothelial and neural cells. Cell Mol Life Sci. 2013; 70(10): 1779-1792, doi: 10.1007/ s00018-013-1312-6, indexed in Pubmed: 23479133.

33. Sawitza I, Kordes C, Reister S, et al. The niche of stellate cells within rat liver. Hepatology. 2009; 50(5): 1617-1624, doi: 10.1002/hep.23184, indexed in Pubmed: 19725107.

34. Chen Y, Zheng S, Qi D, et al. Inhibition of Notch signaling by a $\gamma$-secretase inhibitor attenuates hepatic fibrosis in rats. PLoS One. 2012; 7(10): e46512, doi: 10.1371/journal.pone.0046512, indexed in Pubmed: 23056328.

35. Tugues S, Fernandez-Varo G, Muñoz-Luque J, et al. Antiangiogenic treatment with sunitinib ameliorates inflammatory infiltrate, fibrosis, and portal pressure in cirrhotic rats. Hepatology. 2007; 46(6): 1919-1926, doi: 10.1002/hep.21921, indexed in Pubmed: 17935226.

36. Elsner A, Lange F, Fitzner B, et al. Distinct antifibrogenic effects of erlotinib, sunitinib and sorafenib on rat pancreatic stellate cells. World J Gastroenterol. 2014; 20(24): 7914-7925, doi: 10.3748/wjg.v20.i24.7914, indexed in Pubmed: 24976727.

37. Stockhausen MT, Sjölund J, Axelson H. Regulation of the Notch target gene Hes-1 by TGFalpha induced Ras/MAPK signaling in human neuroblastoma cells. Exp Cell Res. 2005; 310(1): 218-228, doi: 10.1016/j.yexcr.2005.07.011, indexed in Pubmed: 16120441.

38. Papaetis GS, Syrigos KN. Sunitinib: a multitargeted receptor tyrosine kinase inhibitor in the era of molecular cancer therapies. BioDrugs. 2009; 23(6): 377-389, doi: 10.2165/11318860000000000-00000, indexed in Pubmed: 19894779.

39. Shibuya M. VEGFR and type-V RTK activation and signaling. Cold Spring Harb Perspect Biol. 2013; 5(10): a009092, doi: 10.1101/cshperspect.a009092, indexed in Pubmed: 24086040.

40. Cébe-Suarez S, Zehnder-Fjällman A, Ballmer-Hofer K. The role of VEGF receptors in angiogenesis; complex partnerships. Cell Mol Life Sci. 2006; 63(5): 601-615, doi: 10.1007/ s00018-005-5426-3, indexed in Pubmed: 16465447.

41. Yang L, Kwon J, Popov Y, et al. Vascular endothelial growth factor promotes fibrosis resolution and repair in mice. Gastroenterology. 2014; 146(5): 1339-13350.e1, doi: 10.1053/j. gastro.2014.01.061, indexed in Pubmed: 24503129.

42. Duyndam MCA, Hilhorst MC, Schlüper HMM, et al. Vascular endothelial growth factor-165 overexpression stimulates angiogenesis and induces cyst formation and macrophage infiltration in human ovarian cancer xenografts. Am J Pathol. 2002; 160(2): 537-548, doi: 10.1016/s0002-9440(10)64873-0, indexed in Pubmed: 11839574.

43. Hagberg CE, Mehlem A, Falkevall A, et al. Targeting VEGF-B as a novel treatment for insulin resistance and type 2 diabetes. Nature. 2012; 490(7420): 426-430, doi: 10.1038/ nature11464, indexed in Pubmed: 23023133.

44. Villalta SA, Lang J, Kubeck S, et al. Inhibition of VEGFR-2 reverses type 1 diabetes in NOD mice by abrogating insulitis and restoring islet function. Diabetes. 2013; 62(8): 2870-2878, doi: 10.2337/db12-1619, indexed in Pubmed: 23835340.

45. Cha DR, Kim NH, Yoon JW, et al. Role of vascular endothelial growth factor in diabetic nephropathy. Kidney Int Suppl. 2000; 77: S104-S112, indexed in Pubmed: 10997699.

46. Tsai $\mathrm{CH}$, Chiang YC, Chen HT, et al. High glucose induces vascular endothelial growth factor production in human synovial fibroblasts through reactive oxygen species generation. Biochim Biophys Acta. 2013; 1830(3): 2649-2658, doi: 10.1016/j.bbagen.2012.12.017, indexed in Pubmed: 23274526.

47. Brahimi-Horn MC, Pouysségur J. Harnessing the hypoxia-inducible factor in cancer and ischemic disease. Biochem Phar- 
macol. 2007; 73(3): 450-457, doi: 10.1016/j.bcp.2006.10.013, indexed in Pubmed: 17101119.

48. Xiao H, Gu Z, Wang G, et al. The possible mechanisms underlying the impairment of HIF-1 $\alpha$ pathway signaling in hyperglycemia and the beneficial effects of certain therapies. Int J Med Sci. 2013; 10(10): 1412-1421, doi: 10.7150/ijms.5630, indexed in Pubmed: 23983604.
49. Yan J, Zhang Z, Shi H. HIF-1 is involved in high glucose-induced paracellular permeability of brain endothelial cells. Cell Mol Life Sci. 2012; 69(1): 115-128, doi: 10.1007/s00018011-0731-5, indexed in Pubmed: 21617913.

50. Haligur M, Topsakal S, Ozmen O. Early degenerative effects of diabetes mellitus on pancreas, liver, and kidney in rats: an immunohistochemical study. Exp Diabetes Res. 2012; 2012: 1-10, doi: 10.1155/2012/120645, indexed in Pubmed: 22844268.

Submitted: 27 February, 2017 Accepted after reviews: 11 September, 2017 Available as AoP: 19 September, 2017 